\title{
Proton-Mediated Feedback Inhibition of Presynaptic Calcium Channels at the Cone Photoreceptor Synapse
}

\author{
John P. Vessey, ${ }^{1}$ Anna K. Stratis, ${ }^{2}$ Bryan A. Daniels, ${ }^{2}$ Noel Da Silva, ${ }^{2}$ Michael G. Jonz, ${ }^{1}$ Melanie R. Lalonde, ${ }^{1}$ \\ William H. Baldridge, ${ }^{2,3}$ and Steven Barnes ${ }^{1,3}$ \\ Departments of ${ }^{1}$ Physiology and Biophysics, ${ }^{2}$ Anatomy and Neurobiology, and ${ }^{3}$ Ophthalmology and Visual Sciences, Retina and Optic Nerve Research \\ Laboratory, Dalhousie University, Halifax, Nova Scotia, Canada B3H 4H7
}

\begin{abstract}
Generation of center-surround antagonistic receptive fields in the outer retina occurs via inhibitory feedback modulation of presynaptic voltage-gated calcium channels in cone photoreceptor synaptic terminals. Both conventional and unconventional neurotransmitters, as well as an ephaptic effect, have been proposed, but the intercellular messaging that mediates the inhibitory feedback signal from postsynaptic horizontal cells (HCs) to cones remains unknown. We examined the possibility that proton concentration in the synaptic cleft is regulated by HCs and that it carries the feedback signal to cones. In isolated, dark-adapted goldfish retina, we assessed feedback in the responses of HCs to light and found that strengthened $\mathrm{pH}$ buffering reduced both rollback and the depolarization to red light. In zebrafish retinal slices loaded with Fluo-4, depolarization with elevated $\mathrm{K}^{+}$increased Ca signals in the synaptic terminals of cone photoreceptors. Kainic acid, which depolarizes HCs but has no direct effect on cones, depressed the $\mathrm{K}^{+}$-induced Ca signal, whereas CNQX, which hyperpolarizes HCs, increased the Ca signals, suggesting that polarization of HCs alters inhibitory feedback to cones. We found that these feedback signals were blocked by elevated extracellular $\mathrm{pH}$ buffering, as well as amiloride and divalent cations. Voltage clamp of isolated HCs revealed an amiloride-sensitive conductance that could mediate modulation of cleft $\mathrm{pH}$ dependent on the membrane potential of these postsynaptic cells.
\end{abstract}

Key words: cone; fluorescence; horizontal cell; imaging; neurotransmitter; patch clamp; photoreceptor; retina; vision; glutamate; synaptic communication; calcium channels

\section{Introduction}

At the output synapse of cone photoreceptors, horizontal cells (HCs) contribute to the surround receptive field of cones by sending illumination-sensitive inhibitory feedback to the presynaptic cones (Baylor et al., 1971). Inhibitory feedback underlies the formation of center-surround antagonistic receptive fields, which support edge detection, create color opponency, and enhance contrast (Wu, 1992; Burkhardt, 1993; Twig et al., 2003). How this inhibition is generated is not yet understood.

Of several mechanisms proposed (Kamermans and Spekreijse, 1999), the proton model for inhibitory feedback at the cone synapse is attractive for several reasons. First, protons are released along with glutamate from cone synaptic vesicles and inhibit voltage-gated $\mathrm{Ca}$ channels (DeVries, 2001). Proton pumps acidify synaptic vesicles to establish a driving force for glutamate uptake, resulting in vesicles that are $\sim 1.5 \mathrm{pH}$ units

Received Dec. 23, 2004; revised March 9, 2005; accepted March 9, 2005.

This work was supported by Natural Science and Engineering Research Council Grant 0GP194194-01 (W.H.B.) and Canadian Institutes for Health Research Grant MT-10968 (S.B.). M.R.L. was supported by a Canadian Institutes for Health Research/Canadian National Institute for the Blind E. A. Baker studentship award. N.D.S. was supported by the Reynolds Fellowship in Pharmacology at Dalhousie University. M.G.J. was supported by the Nova Scotia Health Research Foundation.

Correspondence should be addressed to Dr. Steven Barnes, Departments of Physiology and Biophysics, and Ophthalmology and Visual Sciences, Dalhousie University, 5859 University Avenue, Halifax, Nova Scotia, Canada B3H 4H7.E-mail: sbarnes@dal.ca.

DOI:10.1523/JNEUROSCI.5253-04.2005

Copyright $\odot 2005$ Society for Neuroscience $\quad 0270-6474 / 05 / 254108-\bullet \$ 15.00 / 0$ more acidic than cytoplasm (Liu and Edwards, 1997). During fusion with the presynaptic membrane, both glutamate and protons are released into the cleft. HCs also extrude protons as a result of normal cell metabolism (Haugh-Scheidt and Ripps, 1998). Second, proton-mediated inhibition of cone calcium channels has been well documented (Barnes and Bui, 1991; Barnes et al., 1993; DeVries, 2001). Protons inhibit Ca channels in two ways. They reduce the conductance of Ca channels by binding to a site in or near the channel pore, interfering with the interaction between charged amino acids and the ions passing through the pore (Prod'hom et al., 1987; Chen et al., 1996). Protons also neutralize fixed negative surface charges on the plasma membrane, shifting Ca channel open probability to more positive voltages (Krafte and Kass, 1988; Klockner and Isenberg, 1994). In an acidic environment, increased membrane depolarization is required to overcome proton inhibition and open the channel. A change of extracellular $\mathrm{pH}$ by 0.1 units yields a shift in calcium channel gating of $\sim 1 \mathrm{mV}$ (Barnes and Bui, 1991).

The negative shift in Ca channel activation caused by surround illumination (Verweij et al., 1996; Hirasawa and Kaneko, 2003 ) could be the result of a pH increase in the synaptic cleft. By increasing the proton buffering capacity of the bathing solution to reduce changes of extracellular $\mathrm{pH}$, feedback-induced responses of both cones and HCs are attenuated (Hirasawa and Kaneko, 2003). Although multiple sources of protons exist, no precise mechanism by which HCs modulate $\mathrm{pH}$ in a voltage- 
dependent manner has been identified. In this paper, we show that, not only is the feedback signal sensitive to increased proton buffering, it is sensitive to amiloride, carbonic anhydrase inhibitors, and the divalent cations nickel and cobalt. A protonconducting ion channel in the $\mathrm{HC}$ dendrites could provide a suitable $\mathrm{pH}$-regulating influence in the synaptic cleft because $\mathrm{HC}$ hyperpolarization would increase the inward driving force on protons, increasing cleft $\mathrm{pH}$, and depolarization would reduce the inward driving force, leaving the cleft more acidic.

\section{Materials and Methods}

Isolated goldfish retina preparation. Ethical approval for use of all species was obtained from the University Committee for Laboratory Animals at Dalhousie University, and all animals were treated in accordance with guidelines set forth by the Canadian Council on Animal Care. All drugs used in these studies were obtained from Sigma (Oakville, Ontario, Canada) unless otherwise stated. Adult goldfish (Carassius auratus) 10-15 $\mathrm{cm}$ in length were maintained in aerated aquaria on a $12 \mathrm{~h}$ light/dark cycle at room temperature. Approximately $3 \mathrm{~h}$ into the light cycle, goldfish were placed in the dark for 15-60 min before they were killed. Under dim red illumination, the goldfish was removed from the water, decapitated, and pithed. Eyes were enucleated, and the anterior part of the eye, including the lens, was removed. The eyecup was inverted onto filter paper, and the optic nerve was severed to free the retina from the eyecup. The retina was then transferred into a superfusion chamber, photoreceptor side up. To prevent the retina from moving within the chamber, a nitrocellulose filter disc (Millipore, Bedford, MA), perforated with seven 4 -mm-diameter holes, was placed on top of the retina. The retina was superfused with bathing medium for 45-90 min at room temperature in the dark before recording commenced. The bathing medium consisted of the following: $100 \mathrm{~mm} \mathrm{NaCl}, 2.5 \mathrm{~mm} \mathrm{KCl}, 1.2 \mathrm{~mm} \mathrm{MgSO}_{4}, 1.0 \mathrm{~mm} \mathrm{CaCl}_{2}$, $20 \mathrm{~mm}$ D-glucose, and $20 \mathrm{~mm} \mathrm{NaHCO}$, bubbled continuously with $97.5 \% \mathrm{O}_{2} / 2.5 \% \mathrm{CO}_{2}$ to produce a $\mathrm{pH}$ of 7.5 or with $95 \% \mathrm{O}_{2} / 5 \% \mathrm{CO}_{2}$ to produce a $\mathrm{pH}$ of 7.2 . Flow rate was maintained at $\sim 1-2 \mathrm{ml} / \mathrm{min}$. HEPES, phosphate, taurine, and Tris were added to the normal bicarbonatebuffered bathing medium. The $\mathrm{pH}$ of these solutions was adjusted by adding of $10 \mathrm{~N} \mathrm{NaOH}$ or $1 \mathrm{~N} \mathrm{HCl}$.

Intracellular microelectrode recording. Borosilicate glass microelectrodes were pulled on a Flaming/Brown model P-97 microelectrode puller (Sutter Instruments, Novato, CA) and filled with $2.5 \mathrm{M} \mathrm{KCl}$. Resistances of the electrodes ranged from 10 to $80 \mathrm{M} \Omega$. Full-field light stimulation was used throughout. Light stimuli were presented using a computer-controlled optical bench, with maximal unattentuated light intensity $\left(I_{\mathrm{o}}\right)$ of $\sim 500 \mu \mathrm{W} / \mathrm{cm}^{2}$. Calibrated neutral density filters, in conjunction with chromatic filters that ranged from 400 to $740 \mathrm{~nm}$ in increments of $20 \mathrm{~nm}$, were used to deliver equal quantal stimuli to the retina. Light stimulus duration was $500 \mathrm{~ms}$. Electrodes were micropositioned (Burleigh Inchworm; Burleigh Instruments, Victor, NY) over an area of the retina with the aid of an infrared camera (Electrophysics Corporation, Nutley, NJ). After a rapid descent to the surface of the retina, the electrodes were stepped through the retina in $4 \mu \mathrm{m}$ increments. Intracellular recordings were amplified using a Dagan Instruments (Minneapolis, MN) 8700 Cell Explorer amplifier and recorded and analyzed using Axoscope 7.0 (Axon Instruments, Union City, CA). HCs were typically encountered $30-50 \mu \mathrm{m}$ below the retina surface, and each of the three types of cone-driven HCs exhibited characteristic responses to chromatic light stimulus (Stell, 1975; Stell and Lightfoot, 1975; Stell et al., 1975; Stell and Harosi, 1976).

Feedback in goldfish $\mathrm{H} 1$ cells was assessed by measuring the rollback response to white light stimuli at $-3.9 \log$ neutral density. Feedback in goldfish $\mathrm{H} 2$ cells was assessed by measuring the depolarizing responses to light stimuli of long wavelengths. Rollback was quantified by subtracting the membrane potential at peak hyperpolarization (typically at $170 \mathrm{~ms}$ ) from the potential when the light stimulus ended $(500 \mathrm{~ms})$. To allow comparison between different cells, rollback was expressed as a fraction of the peak hyperpolarization. For cells that continued to hyperpolarize throughout the light pulse, negative rollback was calculated as the difference between the membrane potential at the end of the stimulus (500 ms) and the membrane potential at $170 \mathrm{~ms}$, the typical time of peak hyperpolarization in cells showing rollback. Negative rollback was expressed as a fraction of the amplitude of maximum hyperpolarization. The feedback responses of $\mathrm{H} 2$ cells were assessed by measuring the amplitude of responses to 660 and $700 \mathrm{~nm}$ equal quantal light stimuli. Responses were then expressed as a fraction of the response to $540 \mathrm{~nm}$ stimulus.

After establishing a criterion $\mathrm{H} 1$ cell rollback of at least $3 \%$ of the peak hyperpolarization in control solutions containing taurine, HEPES, Tris, phosphate, or amiloride were applied for at least $20 \mathrm{~min}$, and the feedback responses of HCs were assessed. Multiple HCs were recorded during a single superfusion condition (control, treatment, or wash), and the cell with the most robust response during that condition was used for analysis.

Zebrafish retinal slice preparations and dye loading. Adult zebrafish (Danio rerio) obtained from local suppliers were housed in a 40 gallon tank at room temperature and kept on a $12 \mathrm{~h}$ light/dark cycle. Zebrafish were killed by decapitation, and their eyes were enucleated. The sclera and lens were removed to form an eyecup, which was then placed in bathing medium that consisted of the following (in mM): $121 \mathrm{NaCl}, 1$ $\mathrm{KCl}, 3 \mathrm{CaCl}_{2}, 1 \mathrm{MgCl}_{2}, 3$ D-glucose, and 4 HEPES at pH 7.4 (Connaughton and Maguire, 1998). While submersed, retinas were isolated from the eyecup and transferred to a glass Petri dish in a small drop of bathing medium. The isolated retinas were then minced with a fine razor blade held in a hemostat, and the resulting minislices (Sun et al., 2002) were transferred to plastic imaging chambers that had been precoated with $0.01 \%$ poly-L-lysine. Once in the imaging chamber, $1 \mathrm{~mm}$ Fluo-4 AM (Molecular Probes, Eugene, OR) in dimethylsulfoxide (DMSO) was added to a final concentration of $10 \mu \mathrm{M}$ (final DMSO concentration of $0.1 \%$ ), and the chamber was left to incubate on ice in the dark for $1 \mathrm{~h}$.

Confocal imaging of retinal slice preparations. Retinal slices loaded with Fluo-4 were imaged on a Nikon (Tokyo, Japan) E800 laser scanning confocal microscope using an argon laser for excitation at $488 \mathrm{~nm}$. Fluorescence emission was recorded by a photomultiplier filtered at $585 \mathrm{~nm}$. Zebrafish retinal slices were observed with a long working distance (2.0 $\mathrm{mm}) 40 \times$ water immersion objective. Bathing media and other experimental solutions were applied via a gravity flow system controlled with an eight-way valve. The flow rate was $1.5 \mathrm{ml} / \mathrm{min}$, and excess fluid was removed by a suction pump. All confocal experiments were performed at room temperature in dim light. Time-lapse movies were captured and analyzed using Nikon EZC1 version 2.0 software. Images were obtained every $15 \mathrm{~s}$ at a resolution of $256 \times 256$ to minimize photobleaching. Fluorescence values were expressed as $\Delta F / F$. To measure $\mathrm{Ca}^{2+}$ signals at the synaptic terminal layer, we delivered pairs of depolarizing stimuli using elevated $\left[\mathrm{K}^{+}\right]$concentration $(15-30 \mathrm{~mm})$ solutions, which were made equiosmotic by decreasing $\mathrm{Na}^{+}$as required. The high $\mathrm{K}^{+}$bathing media were applied for 30-45 s to depolarize all cells of the retina. The amplitudes of the fluorescence increases in response to the pairs of stimuli were measured relative to baseline. The amplitude of the second $\mathrm{Ca}^{2+}$ signal was then expressed as a percentage of the first.

Stock solutions (20 mM) of kainate and CNQX were made in water and DMSO, respectively. After dilution to the final concentration, drugcontaining bathing media were tested for changes in $\mathrm{pH}$. Kainate or CNQX was added $1 \mathrm{~min}$ before and during the test depolarizing stimulus. The effects of kainate and CNQX were assessed by comparing the amplitude of the first signal obtained in the absence of drug with the second signal obtained in its presence. GABA blockers were not used routinely because picrotoxin had no significant effect on the second of the paired stimuli using either kainate ( $\sim 15 \%$ reduction, $n=9 ; p>0.05)$ or CNQX $(\sim 10 \%$ reduction; $n=7 ; p>0.05)$, and it does not appear that GABA mediates feedback (Thoreson and Burkhardt, 1990; Verweij et al., 1996).

Patch-clamp recording from isolated goldfish HCs. Retinas from decapitated goldfish were incubated at room temperature $\left(20-22^{\circ} \mathrm{C}\right)$ for 15 min in papain $(0.5 \mathrm{mg} / \mathrm{ml})$, washed, and triturated in a calcium-free solution containing the following (in $\mathrm{mm}$ ): $120 \mathrm{NaCl}, 2.6 \mathrm{KCl}, 1$ $\mathrm{NaHCO}_{3}, 0.5 \mathrm{NaH}_{2} \mathrm{PO}_{4}, 1 \mathrm{Na}$-pyruvate, $4 \mathrm{HEPES}$, and 16 glucose at $\mathrm{pH}$ 7.4. Isolated HCs, visualized with a Nikon Diaphot microscope, were identified by the several large dendrites emanating from a flat cell body. We used whole-cell ruptured-patch recording techniques to measure currents. Patch electrodes were pulled from hematocrit capillary glass 
(catalog number 15401-659; VWR Scientific, West Chester, PA) on a two-stage pipette puller (model 730; David Kopf Instruments, Tujunga, $\mathrm{CA})$. Electrodes had 5-10 $\mathrm{M} \Omega$ resistance when filled with internal solutions. Aliquots of isolated cells were placed in a recording chamber (volume of $0.5 \mathrm{ml}$ ) and superfused $(1-2 \mathrm{ml} / \mathrm{min}$ ) with an external bathing solution containing the following: $120 \mathrm{~mm} \mathrm{NaCl}, 2.6 \mathrm{~mm} \mathrm{KCl}, 2.5 \mathrm{~mm}$ $\mathrm{CaCl}_{2}, 1 \mathrm{~mm} \mathrm{MgCl}, 10 \mathrm{~mm}$ HEPES, $10 \mathrm{~mm}$ glucose, and $0.1 \mathrm{mg} / \mathrm{ml}$ BSA adjusted to $\mathrm{pH}$ 7.4. The intracellular solution contained the following (in mM): $120 \mathrm{KCl}, 0.5 \mathrm{CaCl}_{2}, 2 \mathrm{MgCl}_{2}, 5 \mathrm{Mg}$-ATP, 10 HEPES, and 5 EGTA, adjusted to $\mathrm{pH}$ 7.2. Membrane currents were recorded with an Axopatch $1-\mathrm{D}$ amplifier (Axon Instruments), filtered at $1 \mathrm{kHz}(-3 \mathrm{~dB}$, four-pole Bessel), and digitized at $2 \mathrm{kHz}$ using an Indec Systems (Sunnyvale, CA) interface for computer storage. Stimulus generation and data acquisition were controlled by BASIC-FASTLAB program software (Indec Systems). Current-voltage $(I-V)$ relationships were generated by averaging current magnitude in the last $25 \mathrm{~ms}$ of each $100 \mathrm{~ms}$ voltage step. Conductance was measured as the slope of the $I-V$ relationship between -70 and $-20 \mathrm{mV}$ and percentage reduction of this defined as $\left[1-\left(I_{\text {test }}\right) /\right.$ $\left.\left(I_{\text {control }}\right)\right] \times 100$.

Statistical analysis. All imaging data were tested for statistical significance by performing nonparametric Mann-Whitney rank sum tests and expressed as SEM. Data were considered significant if $p<0.05$. All microelectrode data were also tested for significance with nonparametric tests. Mann-Whitney and Kruskal-Wallis tests were used to determine whether differences between control, treatment, and wash were statistically significant. Nondirectional $p$ values were used, and differences between treatments were considered significant if $p<0.05$.

\section{Results \\ Proton buffering reduces the feedback response of horizontal cells}

The proton buffers HEPES ( $\mathrm{p}_{\mathrm{Ka}}$ of 7.5) and Tris ( $\mathrm{p}_{\mathrm{Ka}}$ of 8.3) reduced the feedback responses of both luminosity-type ( $\mathrm{H} 1)$ and chromaticity-type (H2) HCs in isolated goldfish retina. H1 HCs recorded under control conditions $(97.5 \% / 2.5 \%$ carbogenbubbled, bicarbonate-based bath solution, $\mathrm{pH}$ 7.5) exhibited the characteristic rollback during the hyperpolarizing response to full-field, full-spectrum illumination of $500 \mathrm{~ms}$ duration (Fig. $1 A, B)$. Rollback consisted of a gradual depolarization that followed the initial rapid hyperpolarization in response to light, beginning $\sim 170 \mathrm{~ms}$ after stimulus onset. At the end of the stimulus, there was a rapid return to the dark-resting membrane potential, sometimes with an overshoot. As illustrated by the examples in Figure 1, $A$ and $B$, superfusion with either 10 mM HEPES or Tris (both $\mathrm{pH}$ 7.5) for at least $20 \mathrm{~min}$, eliminated $\mathrm{H} 1$ cell rollback. In fact, $\mathrm{H} 1$ cells recorded in HEPES or Tris continued to hyperpolarize throughout the duration of the light stimulus. Similar results were obtained in all retinas studied $(n=9$ for HEPES; $n=6$ for Tris). Before superfusion with HEPES, the rollback of H1 HCs amounted to a $9 \pm 1 \%$ erosion of the peak hyperpolarization. In every $\mathrm{H} 1$ cell recorded, treatment with 10 mM HEPES blocked rollback, and instead there was a $22 \pm 3 \%$ increase in the hyperpolarizing response over the same time period $(p<0.001)$. With Tris buffer, rollback $(11 \pm 1 \%)$ was replaced by a $16 \pm 1 \%$ additional hyperpolarization when retinas were treated with $10 \mathrm{~mm}$ Tris $(p<0.01)$ (Fig. $1 B)$. In some experiments, it was possible to obtain recordings of $\mathrm{H} 1$ cells after 20 min superfusion with control bathing solution after treatment with HEPES or Tris (wash). In these cells, rollback returned ( $5 \pm$ 2 and $8 \pm 2 \%$ of peak hyperpolarizing response) after HEPES $(n=3)$ and Tris $(n=5)$, respectively. Hare and Owen (1998) found that the amplitude of horizontal cell light responses was dramatically increased when bicarbonate buffers were replaced with HEPES (pH 7.8) and that the cells depolarized by $\sim 30 \mathrm{mV}$ in addition to other effects, consistent with cytoplasmic alkaliniza-
A
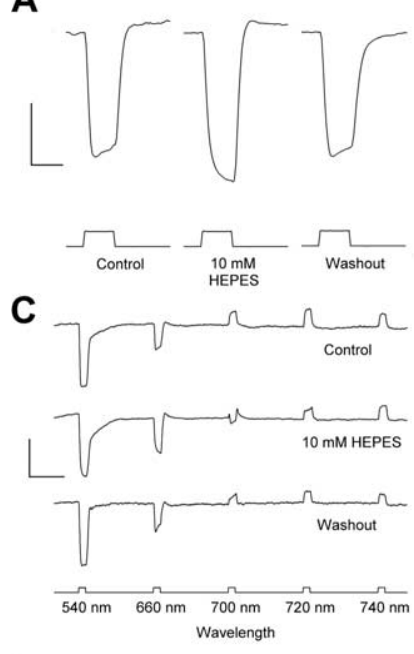

E

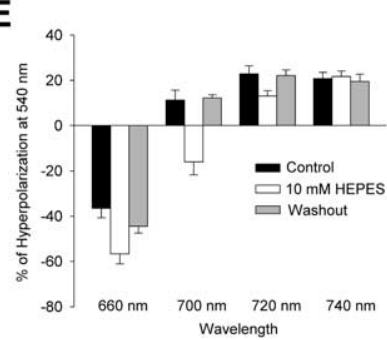

B
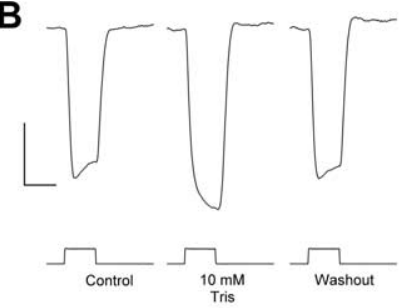

D

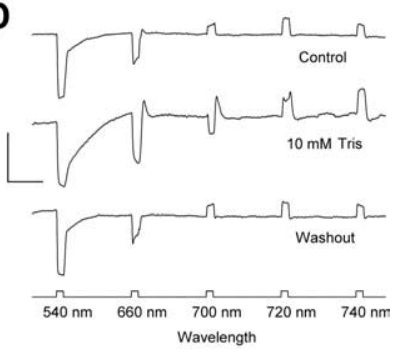

$\mathbf{F}$

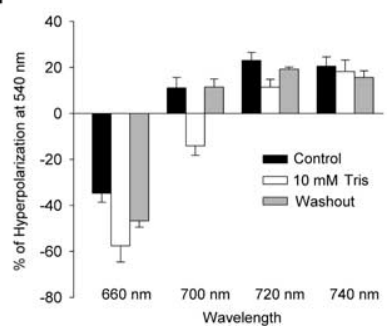

Figure 1. Increased pH buffering reduces the feedback response of horizontal cells. $\boldsymbol{A}, \boldsymbol{B}$, Representative recordings from six different $\mathrm{H} 1 \mathrm{HC}$ in response to full-field illumination in a retina before (left trace), during (middle trace), and after (right trace) $10 \mathrm{~mm}$ HEPES $(\boldsymbol{A})$ and Tris $(B)$ were added to the bicarbonate-buffered bathing medium. Both HEPES and Tris abolished the rollback in the waveform of the $\mathrm{HC}$ response. Calibration: $10 \mathrm{mV}, 500 \mathrm{~ms}$. C, D, Representative recordings from six different $\mathrm{H} 2 \mathrm{HCs}$ in response to equal quanta 540,660, and $700 \mathrm{~nm}$ stimuli in a retina before (top trace), during (middle trace), and after (bottom trace) treatment with $10 \mathrm{~mm}$ HEPES (C) or Tris (D). Both HEPES and Tris blocked the depolarizing response to 700 $\mathrm{nm}$ stimuli and increased the amplitude of the hyperpolarizing response to $660 \mathrm{~nm}$ stimuli. The amplitude of the response to $540 \mathrm{~nm}$ was not affected by either HEPES or Tris. Calibration: 20 $\mathrm{mV}, 2.5 \mathrm{~s}$. $\boldsymbol{E}, \boldsymbol{F}$, Mean response to 660 and $700 \mathrm{~nm}$ stimuli in all cells studied expressed as a percentage of the response to $540 \mathrm{~nm}$ stimuli. Both $10 \mathrm{~mm}$ HEPES $(\boldsymbol{E})$ and Tris $(\boldsymbol{F})$ increased the mean response to $660 \mathrm{~nm}$ stimuli and inverted the response to $700 \mathrm{~nm}$ stimuli.

tion. In contrast, we added HEPES to the bicarbonate-buffered saline, and we did not observe such large changes in the light response.

HEPES and Tris also decreased feedback responses in $\mathrm{H} 2 \mathrm{HCs}$. Under control conditions, these cells hyperpolarized in response to equiquantal 540 and $660 \mathrm{~nm}$ stimuli, but the response to the $700 \mathrm{~nm}$ stimulus was depolarizing (Fig. 1C,D). After at least 20 min superfusion with $10 \mathrm{~mm}$ HEPES or Tris, the responses of $\mathrm{H} 2$ cells were dramatically altered. As illustrated in Figure 1, D and $E$, the most obvious change was the decrease in the depolarization at $700 \mathrm{~nm}$. Although the waveform of the responses to this stimulus was now complex, a clear hyperpolarizing component became apparent after treatment with HEPES or Tris. Also apparent was an increase in the response to the $660 \mathrm{~nm}$ stimulus. Similar results were obtained in all retinas studied (Fig. $1 E, F$ ). To permit comparison between cells, mean responses were determined after being normalized to the response to a $540 \mathrm{~nm}$ stimulus. Compared with control conditions, the mean response to $660 \mathrm{~nm}$ stimuli was greater $(p<0.01)$ in the presence of HEPES $(n=6)$ or Tris $(n=6)$. The mean response to $700 \mathrm{~nm}$ stimulus was decreased or inverted $(p<0.05)$. In some retinas, it was possible to reverse the effect of HEPES or Tris by washing with control medium. As 
illustrated for an individual case in Figure 1, $C$ and $D$, and for the mean (Fig. 1E,F), wash returned the responses at each wavelength to near control values.

Two other proton buffers were also tested (data not shown). Taurine (10 mM; $\mathrm{p}_{\mathrm{Ka}}$ of 9.1) also reduced rollback in $\mathrm{H} 1$ cells but was less effective than HEPES or Tris. In some cells, rollback was abolished, but in others it was only reduced. $\mathrm{H} 1$ cells recorded under control conditions showed rollback $(8 \pm 1 \%$; $n=6)$, but cells recorded in these retinas after treatment with $10 \mathrm{~mm}$ taurine did not $(p<0.05)$, instead showing, on average, a gradual hyperpolarization $(6 \pm 11 \%)$ from $170 \mathrm{~ms}$ to the end of the light stimulus. After wash, rollback in $\mathrm{H} 1$ cell responses returned $(10 \pm 2 \% ; n=5)$. Taurine also affected the responses of $\mathrm{H} 2$ cells but much less than HEPES or Tris. On average, the only significant difference was the decrease and small inversion of the mean response to $700 \mathrm{~nm}$ stimuli ( $p<0.05 ; n=5)$. Dibasic phosphate $\left(10 \mathrm{~mm} ; \mathrm{p}_{\mathrm{Ka}}\right.$ of 2.7$)$ was even less effective: it did not abolish rollback in $\mathrm{H} 1$ cells $(n=5)$ and had no effect on the responses of $\mathrm{H} 2 \mathrm{HCs}(n=3)$.

To determine whether the effect of proton buffers on the feedback responses of HCs depended on the nominal $\mathrm{pH}$ of the buffer solution, we tested the effect of Tris at $\mathrm{pH} 7.2$ and 8.2 (data not shown). In both cases (each $n=3$ ), the rollback of H1 HCs was abolished and the magnitude of the resulting purely hyperpolarizing response was not significantly different from that obtained when $\mathrm{pH} 7.5$ Tris was used $(p<0.05)$ (Fig. $1 B)$.

\section{Imaging calcium dynamics at the photoreceptor synapse during modulation of postsynaptic AMPA receptors}

To determine the site of action of the proton buffers on the feedback signal, we measured calcium dynamics at photoreceptor synaptic terminals in zebrafish retinal slices (Fig. 2A). When loaded with the calcium indicator dye Fluo-4, the photoreceptors fluoresced strongly, and their synaptic terminals could be easily visualized (Fig. $2 \mathrm{~B}$ ). The lack of fluorescence in the inner retina was likely attributable to the poor penetration of the AM form of Fluo-4 into the bulk thickness of the slice. Because the outer segments of the photoreceptors were in contact with the dyeloading external bathing medium, photoreceptors loaded more or less uniformly. During depolarization with an enriched potassium solution (15-30 mM), the fluorescence of the synaptic terminal layer increased measurably (Fig. $2 C, D$ ). A response to the depolarizing stimulus was characterized by a $\Delta F / F$ value $>0.1$.

Kainic acid (kainate), an AMPA/kainate receptor agonist, and CNQX, an AMPA/kainate receptor antagonist, were used to manipulate HC feedback. Initially, each drug was applied to Fluo-4loaded zebrafish retinal slices in the absence of any depolarizing stimuli. When applied to the retina for $1 \mathrm{~min}, 50 \mu \mathrm{M}$ kainate caused a large and sustained increase in $\left[\mathrm{Ca}^{2+}\right]_{\mathrm{i}}$ in the upper margin of the inner nuclear layer, a region containing the AMPA receptor-expressing cell bodies of HCs (Morigiwa and Vardi, 1999). Consistent with the findings of Tachibana and Kaneko (1988) that cone photoreceptors are not sensitive to kainate, we found that kainate did not increase fluorescence in the synaptic terminals of the photoreceptors (Fig. $3 A-C$ ). Washout of the drug could not be achieved in the time course of these experiments. This was not surprising because the effects of a short exposure to micromolar concentrations of kainate have been shown to persist in cells of the retina for up to $10 \mathrm{~min}$ (Baldridge, 1996). No effect on cells of the inner nuclear layer were found with a 1 min exposure to $50 \mu \mathrm{M}$ CNQX. CNQX, by antagonizing the AMPA receptors, should hyperpolarize the HCs by blocking synaptic input and consequently reduce $\left[\mathrm{Ca}^{2+}\right]_{i}$. Because the
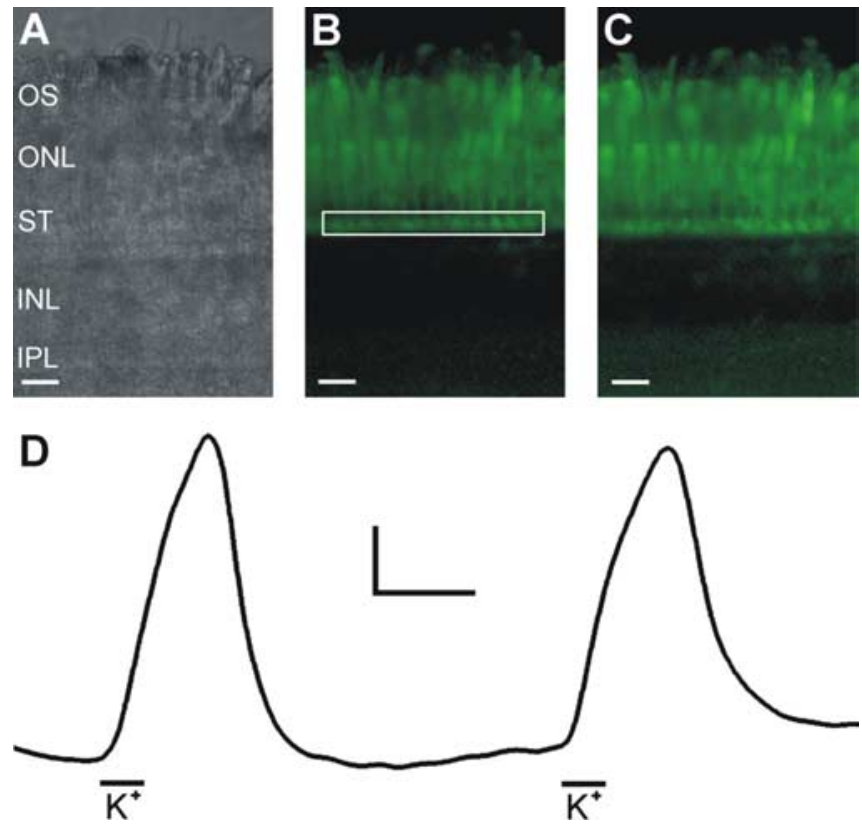

Figure 2. $\quad \mathrm{Ca}^{2+}$ signal dynamics in cone photoreceptor synaptic terminals. A, A differential interference contrast image of a zebrafish retinal slice displaying the photoreceptor outer segments (OS), the outer nuclear layer (ONL), the photoreceptor synaptic terminals (ST), the inner nuclear layer (INL), and the upper portion of the inner plexiform layer (IPL). $\boldsymbol{B}$, Confocal fluorescence image recorded from the same slice at $585 \mathrm{~nm}$ in response to excitation at $488 \mathrm{~nm}$. Because of the contact of their outer segments with the bathing medium, photoreceptors load with Fluo-4 AM, whereas cells in the interior of the slice do not, allowing for visualization of the photoreceptor synaptic terminals. $\boldsymbol{C}$, The same slice after a brief exposure to an elevated $\left[\mathrm{K}^{+}\right]$ depolarizing stimulus. $\boldsymbol{D}$, Time course of fluorescence intensity changes in the synaptic terminal layer in response to the depolarizing stimuli. The box in $\boldsymbol{B}$ indicates the area of measurement. During exposure to the paired depolarizing stimuli, indicated by the black bars below the trace $\left(\mathrm{K}^{+}\right)$, the synaptic terminals of the photoreceptors displayed an increase in fluorescence corresponding to an increase in $\left[\mathrm{Ca}^{2+}\right]_{\mathrm{i}}$ in the synaptic terminals. Scale bars, $15 \mu \mathrm{m}$. Calibration: $0.2 \Delta F / F, 90 \mathrm{~s}$.

cells of the inner retina do not readily load with the dye (Fig. 2), it was impossible to detect reductions in $\mathrm{Ca}^{2+}$ concentrations because the baseline fluorescence was too low. However, CNQX caused fluorescence increases in both the synaptic terminals and cell bodies of the photoreceptors in all retinas tested $(n=3)$ (Fig. $3 D-F)$. This effect was reminiscent of the slow spikes recorded in cones during surround receptive field stimulation, which produces hyperpolarization of horizontal cells (Piccolino and Gerschenfeld, 1980) and might reflect loss of feedback-induced Ca channel inhibition, leading to $\mathrm{Ca}$ channel-mediated regenerative depolarizations. Increases in fluorescence could include the effects of $\mathrm{Ca}^{2+}$-induced $\mathrm{Ca}^{2+}$ release from intracellular $\mathrm{Ca}^{2+}$ stores.

It seemed possible that, by modulating $\mathrm{HC}$ membrane potential with kainate and CNQX, the level of inhibitory feedback signal originating from these cells could vary and, in turn, affect presynaptic $\left[\mathrm{Ca}^{2+}\right]_{\mathrm{i}}$. To test this, paired depolarizing stimuli were delivered. The first stimulus was given in the absence of any drug, whereas the second was accompanied by either $50 \mu \mathrm{m}$ kainate or CNQX. Control experiments yielded two increases in $\left[\mathrm{Ca}^{2+}\right]_{\mathrm{i}}$ in the synaptic terminals of approximately the same amplitude, as illustrated in Figure 2D. When expressed as a percentage of the first, the second stimulus peak amplitude was reduced by $7 \pm 1 \%(n=4)$ (Fig. $4 I$, middle bar). This slight reduction may be attributable to photobleaching of the calcium indicator dye. Kainate had the significant effect of reducing the $\mathrm{Ca}^{2+}$ signal 
to $60 \pm 5 \%(n=7 ; p<0.01)$ of control (Fig. 4A-D). CNQX had the opposite effect, significantly increasing the $\mathrm{Ca}^{2+}$ signal by $61 \pm 5 \%(n=5 ; p<0.05)$ (Fig. $4 E-H)$, similar to the effect of CNQX shown in Figure $3 F$, but here synchronized by the action of the elevated $\left[\mathrm{K}^{+}\right]$. The histogram in Figure $4 I$ summarizes these observations, which are consistent with recent direct measurement of cone Ca channel current modulation by kainate and CNQX (Hirasawa and Kaneko, 2003).

\section{Increased $\mathrm{pH}$ buffering reduces the enhancement and suppression of presynaptic $\left[\mathrm{Ca}^{2+}\right]_{i}$ caused by CNQX and kainate, respectively}

To test the role of protons in the inhibitory feedback mechanism from HCs to cones, we increased the $\mathrm{pH}$ buffering capacity of the bathing solution by adding $32.5 \mathrm{~mm}$ bicarbonate or by increasing the HEPES concentration to 20 or $30 \mathrm{~mm}$ from the standard $4 \mathrm{~mm}$. By adding $32.5 \mathrm{~mm}$ bicarbonate to the bathing solution, the effects of both kainate and CNQX were attenuated. Bicarbonate reduced the $\mathrm{Ca}^{2+}$ signal inhibition by kainate to an amount $45 \pm$ $4 \%(n=4 ; p<0.05)$ less than control and also significantly limited the increase of $\mathrm{Ca}^{2+}$ signal by CNQX to $32 \pm 8 \%(n=3$; $p<0.05)$ over control. Increasing the HEPES concentration also led to significant attenuation of the effects produced by both kainate and CNQX. HEPES at $20 \mathrm{~mm}$ caused a complete elimination of the CNQX-mediated increase in $\mathrm{Ca}^{2+}$ signal (second peak now $4 \pm 4 \%$ less than control; $p<0.01 ; n=6$ ) and significantly limited the kainate-mediated decrease in the $\mathrm{Ca}^{2+}$ signal to a reduction of only $39 \pm 6 \%$ $(n=7 ; p<0.05)$. An additional increase of buffer capacity, using $30 \mathrm{~mm}$ HEPES, led to an even greater attenuation of the kainate-mediated decrease, now reduced to $18 \pm 7 \%(p<0.001 ; n=6)$ of control. A summary of these effects of increased proton buffering is presented in Figure 5.

By comparing the amplitude of depolarization-induced calcium signals at specific buffered $\mathrm{pH}$ values with the values observed during $\mathrm{HC}$ membrane potential manipulation, we should be able to estimate the $\mathrm{pH}$ changes occurring normally in the cleft. At pH 6.6, the $\mathrm{Ca}^{2+}$ signal amplitude was $78 \pm 4 \%(n=3)$ less than that obtained at $\mathrm{pH}$ 7.4. At $\mathrm{pH} 7.0$, the $\mathrm{Ca}^{2+}$ signal was reduced to $62 \pm 6 \%$ $(n=3)$ of control. In conditions more basic, $\mathrm{Ca}^{2+}$ signals were enhanced. At $\mathrm{pH} 7.8$, the $\mathrm{Ca}^{2+}$ signal was $52 \pm 6 \%(n=$ 4) greater than the control signal elicited at $\mathrm{pH} 7.4$, and at $\mathrm{pH}$ 8.2 , the $\mathrm{Ca}^{2+}$ signal was $91 \pm 5 \%(n=3)$ greater than that of control. Representative fluorescence intensity time courses
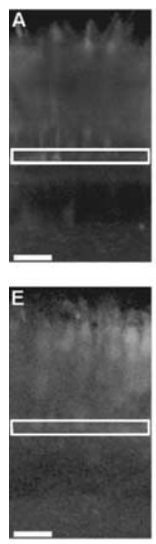
the mean \pm SEM.
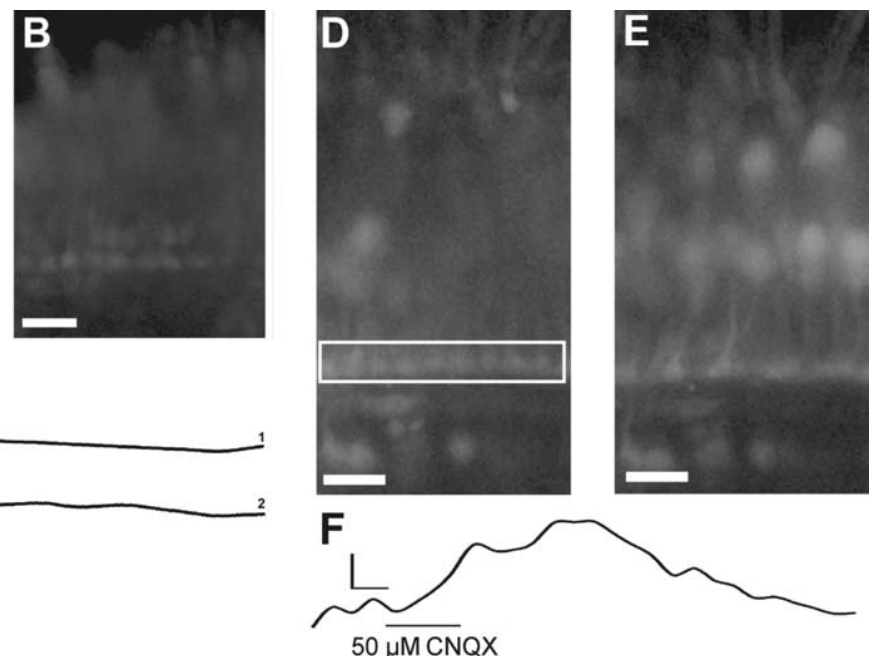

Figure 3. Kainate and CNQX differentially alter calcium signals in outer retinal neurons. $A, D$, Baseline fluorescence images of individual retinal slices. $\boldsymbol{B}, \boldsymbol{E}$, Fluorescence images of the same slices after a 1 min exposure to either $50 \mu \mathrm{m}$ kainate $(\boldsymbol{B})$ or $50 \mu \mathrm{m}$ CNQX $(\boldsymbol{E})$. Scale bars, $15 \mu \mathrm{m}$. $\boldsymbol{C}$, Time course of fluorescence intensity in two regions of the retinal slice during the application of kainate. The synaptic terminals of the photoreceptors (box 1 in $\boldsymbol{B}$; trace 1 in $\boldsymbol{C}$ ) did not respond to kainate with a change in fluorescence. Cells of the inner nuclear layer (box 2 in $\boldsymbol{B}$; trace 2 in $\boldsymbol{C}$ ) respond with a large and sustained increase in fluorescence during exposure to kainate, consistent with a selective action of kainate to depolarize HCS. D, Time course of fluorescence intensity of the synaptic terminals during the application of CNQX. The terminals, along with the cell bodies, responded with large unsynchronized increases in fluorescence. Calibration: $30 \mathrm{~s}, 0.05 \Delta \mathrm{F} / \mathrm{F}$.
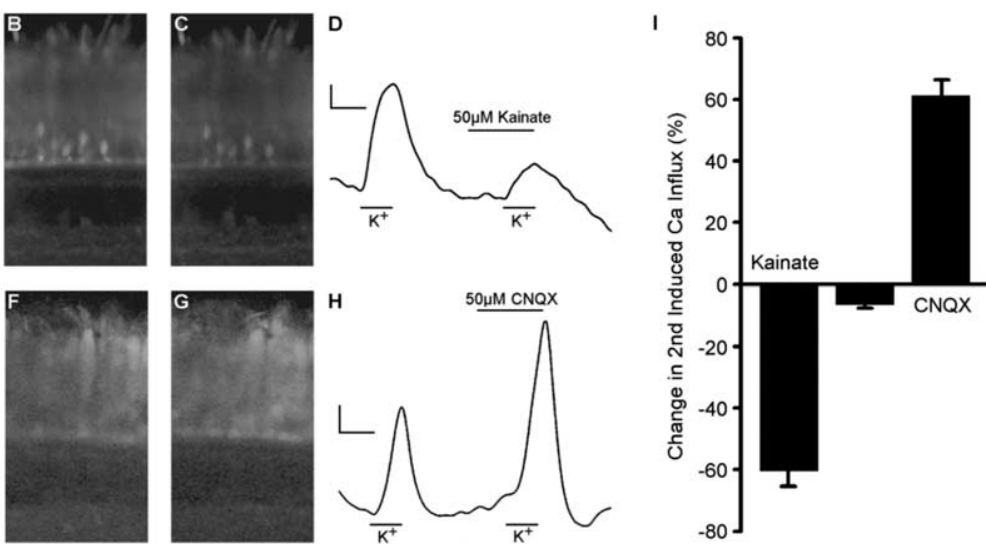

Figure 4. Feedback inhibition is modulated by kainate and CNQX. $\boldsymbol{A}, \boldsymbol{E}$, Baseline fluorescence images of individual retinal slices $\boldsymbol{B}, \boldsymbol{F}$, Peak fluorescence images of the same retinal slices after a brief $\mathrm{K}^{+}$depolarization-induced increase in $\left[\mathrm{Ca}^{2+}\right]_{\mathrm{i}}$. C, $\mathbf{G}$, Peak fluorescence images of a second $\mathrm{K}^{+}$depolarization-induced increase in $\left[\mathrm{Ca}^{2+}\right]_{\mathrm{i}}$ in the presence of either $50 \mu \mathrm{m}$ kainate $(\boldsymbol{C})$ or 50 $\mu \mathrm{M}$ CNQX $(\boldsymbol{G})$. Scale bars, $15 \mu \mathrm{m}$. $\boldsymbol{D}, \boldsymbol{H}$, Time course of fluorescence intensity measured at the photoreceptor synaptic terminal layers, indicated by the boxes in $\boldsymbol{A}$ and $\boldsymbol{E}$, during the application of either kainate or CNQX. The depolarizing stimuli are indicated by the bars below each trace $\left(\mathrm{K}^{+}\right)$. Kainate and $\mathrm{CNQX}$ were added $1 \mathrm{~min}$ before and during the second depolarization stimulus. Calibration: $90 \mathrm{~s}, 0.1 \Delta$ F/F.I, Histogram summarizing the effects of kainate and CNQX on the amplitudes of fluorescence increase of the second depolarizing stimuli. The middle bar shows the modest $7 \%$ decline in second peak amplitude in the absence of any drugs. The amplitude of the second $\mathrm{Ca}^{2+}$ signal is expressed as a percentage of the first, and summarized data are expressed as

are illustrated in Figure $6 \mathrm{~A}$. These data could be fit with a logistical equation ranging between 96.2 and $-86.3 \%$, with a slope factor of 0.27 and an $\mathrm{EC}_{50}$ of 7.48 (Fig. $6 \mathrm{~B}$ ). As a first approximation, considering the $\sim 60 \%$ reduction of $\left[\mathrm{Ca}^{2+}\right]_{\mathrm{i}}$ by $50 \mu \mathrm{M}$ kainate and $60 \%$ increase by $50 \mu \mathrm{M}$ CNQX, these measurements suggest that kainate depolarization of the HC leads to a synaptic cleft acidification to a value near $\mathrm{pH}$ 6.9, whereas CNQX produces alkalinization of the synaptic cleft to a value near $\mathrm{pH} 7.9$. 
A $50 \mu \mathrm{M}$ Kainate
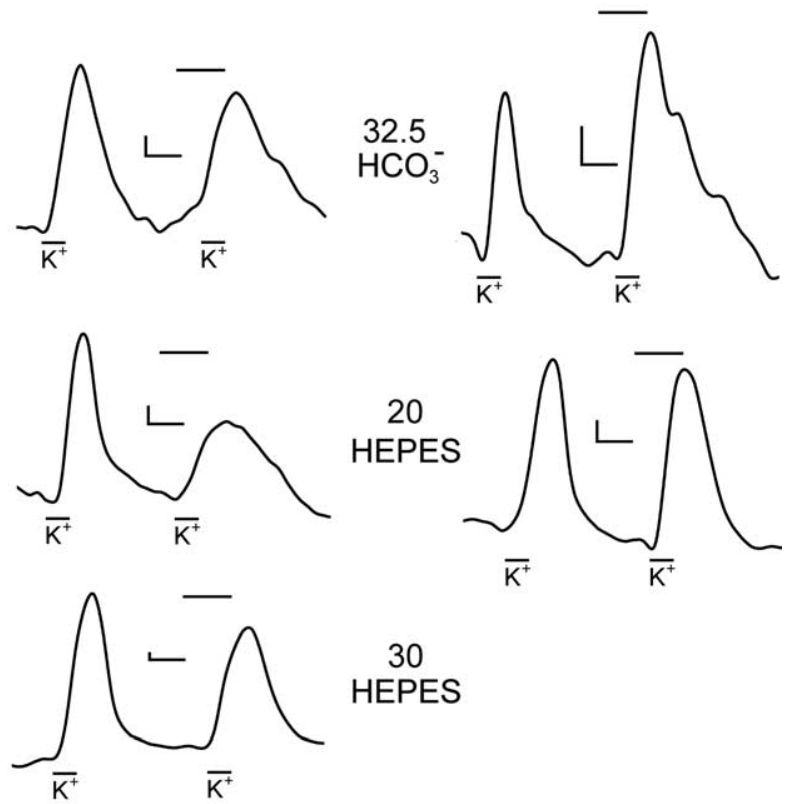

30 HEPES

B

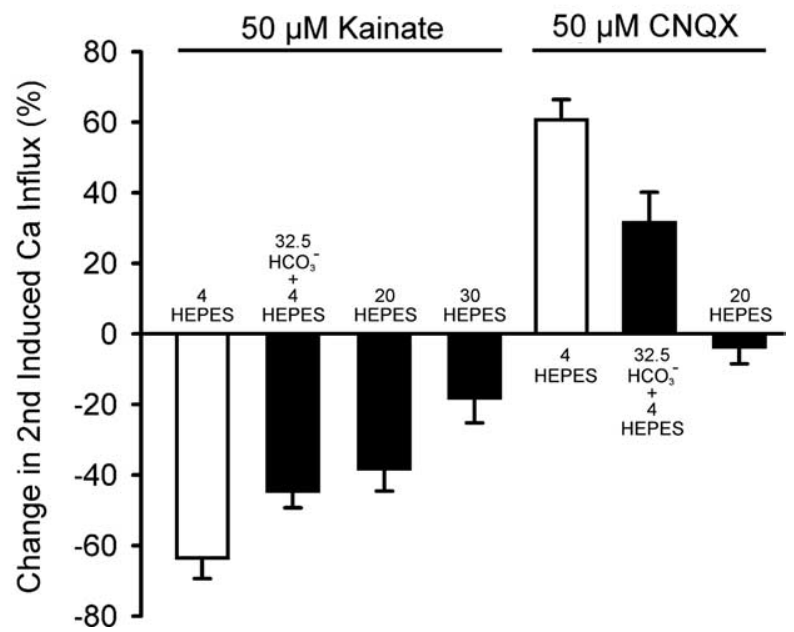

Figure 5. Proton buffering limits the effect of feedback inhibition. $A$, Time course fluorescence intensity traces demonstrating the significant impact of increased $\mathrm{pH}$ buffering on the effects of both by $50 \mu \mathrm{m}$ kainate (left column) and $50 \mu \mathrm{M}$ CNQX (right column; drug applications indicated by the black bars below each trace; elevated $\left[\mathrm{K}^{+}\right]$depolarizing stimuli as per Fig. 2). Bathing medium containing both $32.5 \mathrm{~mm}$ bicarbonate $\left(\mathrm{HCO}_{3}^{-}\right)$and 4 mM HEPES reduced the effects elicited by kainate and CNQX. Medium containing $20 \mathrm{~mm}$ HEPES also attenuated the effects of kainate. HEPES at $20 \mathrm{~mm}$ completely abolished the effects of CNQX. An additional increase to $30 \mathrm{~mm}$ HEPES caused an even greater attenuation of the kainate-induced reduction of the $\mathrm{Ca}^{2+}$ signal. Calibration: $90 \mathrm{~s}, 0.1 \Delta F / F$. B, Histogram showing the mean \pm SEM effects of $\mathrm{pH}$ buffering on the response ratios obtained with kainate and CNQX. The decrease of the response ratio attributable to kainate was significantly attenuated by the addition of $32.5 \mathrm{~mm}$ bicarbonate or an increase in HEPES from 4 to $20 \mathrm{~mm}$. An additional increase in HEPES to $30 \mathrm{~mm}$ led to an even greater attenuation of the kainate-induced decrease in response ratio. Bicarbonate significantly reduced the effect of CNQX, whereas $20 \mathrm{~mm}$ HEPES completely abolished it. Open bars show control data from Figure 4 ( $4 \mathrm{~mm}$ HEPES).

Feedback is sensitive to a reduction in proton driving force and ion channel/transporter blockers

What membrane mechanism might HCs use to regulate cleft $\mathrm{pH}$ in a voltage-dependent manner? If the data presented so far suggest that a decrease in cleft proton concentration accompanies $\mathrm{HC}$ hyperpolarization, this might be accomplished by diffusion of protons down their electrochemical gradient, in which case,
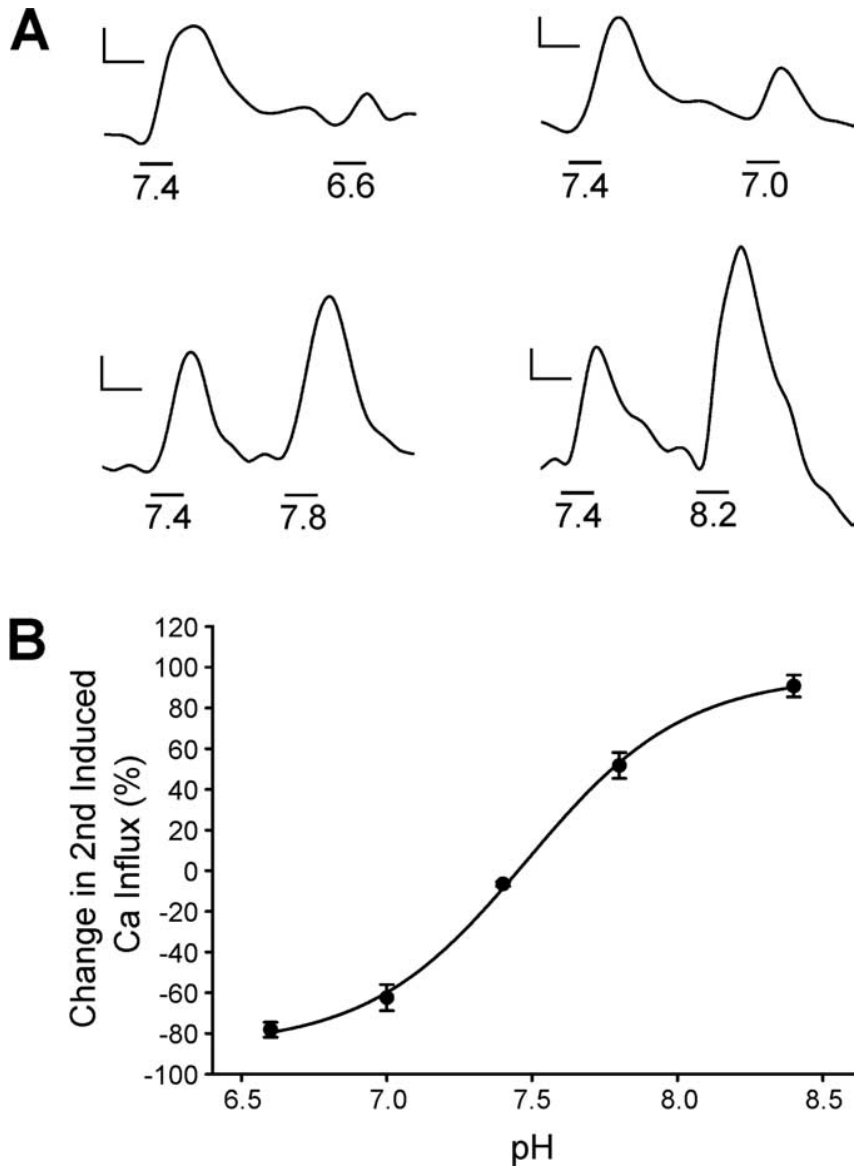

Figure 6. Proton modulation of cone Ca channels. $\boldsymbol{A}$, Time course fluorescence intensity traces demonstrate the relationship between $\mathrm{pH}$ and $\mathrm{Ca}$ channel activity. The traces were obtained with paired elevated $\left[\mathrm{K}^{+}\right]$depolarizing stimuli together with $\mathrm{pH}$ changes, as shown by the black timing bars below the fluorescence intensity traces. When subjected to depolarizing stimuli more acidic than control, the second signal was reduced in amplitude (top traces). More basic conditions produced less inhibition of presynaptic $C a$ channels, and subsequently greater $\mathrm{Ca}^{2+}$ signals were seen with depolarization (bottom traces). Calibration: $90 \mathrm{~s}, 0.1 \Delta$ F/F. B, Fit with a logistical function, the $\mathrm{pH}-$ response curve has a midpoint of $\mathrm{pH} 7.48$.

simple depletion of an inward proton gradient across the cell membrane or interference with proton conductance mechanisms should reduce that regulatory ability. To begin examining this, we used methazolamide, a carbonic anhydrase inhibitor, to acidify the cytoplasm of HCs. Inhibition of carbonic anhydrase should cause proton concentrations to rise in the cell body, an effect found previously in cultured astrocytes (Chow et al., 1991, 1992). By acidifying the intracellular compartment, the proton driving force would be decreased, and, when hyperpolarized, HCs ought not be able to alkalinize the synaptic cleft via increased proton influx.

Repeating the investigations of cone terminal calcium signals with kainate and CNQX but now in the presence of $100 \mu \mathrm{M}$ methazolamide, only significant changes to the CNQX-induced increases in $\mathrm{Ca}^{2+}$ signal were found (Fig. $7 A$ ). In the presence of both CNQX and methazolamide, $\left[\mathrm{Ca}^{2+}\right]_{\mathrm{i}}$ was $14 \pm 9 \%(n=6)$ less than control, a significant change from the $61 \%$ increase found with CNQX alone. In the presence of both kainate and methazolamide, $\left[\mathrm{Ca}^{2+}\right]_{\mathrm{i}}$ was reduced to $57 \pm 5 \%(n=10)$ of control, a value of no significant difference from experiments with kainate alone. This is not surprising because the action of kainate is to depolarize the HCs, and this alone would have the effect of less- 
A

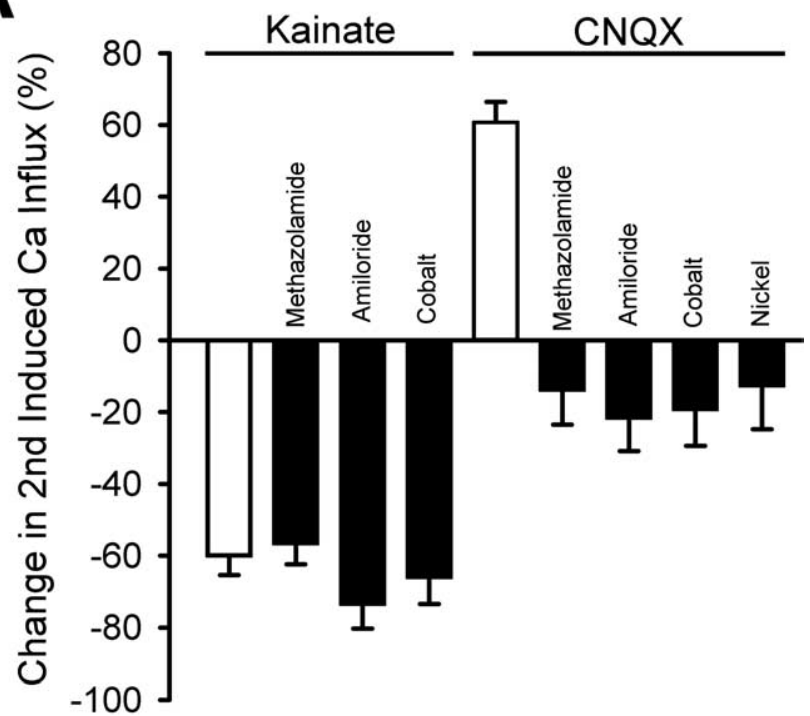

B
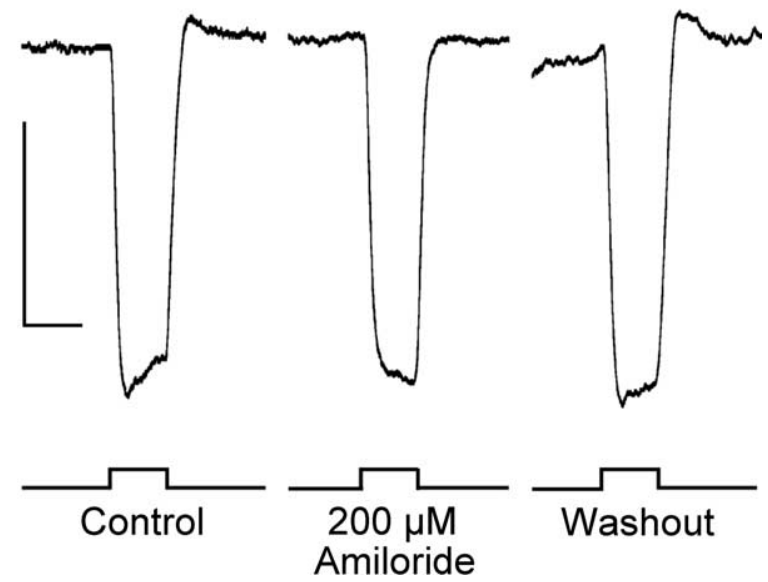

Figure 7. The feedback signal is sensitive to a reduction in proton driving force, amiloride, and divalent cations. $\boldsymbol{A}, \mathrm{A}$ summary histogram displaying the mean \pm SEM effects of various blockers of the feedback signal. CNQX, by hyperpolarizing HCs, increases the proton driving force into the $\mathrm{HC}$ dendrites. This increase in driving force is sensitive to methazolamide, a carbonic anhydrase inhibitor, amiloride, and both nickel and cobalt. Kainate reduces the proton driving force by depolarizing the HCs. None of the agents had a significant impact on the kainate effect. Open bars show control data from Figure 4. $B$, Representative intracellular $\mathrm{H} 1$ recordings showing the elimination of rollback in the presence of $200 \mu \mathrm{m}$ amiloride (middle trace) and the recovery of rollback during washout (right trace). Calibration: $500 \mathrm{~ms}, 10 \mathrm{mV}$.

ening the proton driving force, similar to the expected effect of carbonic anhydrase inhibition with methazolamide.

Similar effects on feedback were found with amiloride, a known blocker of sodium/proton exchangers (Aickin and Thomas, 1977) and epithelial Na channels (ENaCs) (Garty and Benos, 1988). When tested in the presence of $50 \mu \mathrm{M}$ amiloride, CNQX had only a small inhibitory effect on the $\mathrm{Ca}^{2+}$ signal $(22 \pm$ $9 \%$ reduction; $n=10$ ), a stark contrast to the $61 \%$ signal increase seen with control treatments of CNQX. Amiloride produced no significant changes to the effects of kainate ( $74 \pm 6 \%$ reduction; $n=5)$. Similarly, the CNQX-induced increase in $\mathrm{Ca}^{2+}$ signal also proved to be sensitive to submillimolar concentrations of both cobalt and nickel. In the presence of $250 \mu \mathrm{M} \mathrm{Co}{ }^{2+}$, the $\mathrm{Ca}^{2+}$ signal was reduced by $20 \pm 10 \%(n=9)$ compared with control. $\mathrm{Ni}^{2+}$ at $250 \mu \mathrm{M}$ had a similar effect, reducing the $\mathrm{Ca}^{2+}$ signal by $13 \pm 12 \%(n=9) . \mathrm{Co}^{2+}$ did not elicit any significant change in the responses obtained in the presence of kainate, in which the $66 \pm 7 \%(n=5)$ reduction was similar to that seen in control. A selective, inhibitory action of $\mathrm{Ni}$ and $\mathrm{Co}$ on surround-induced feedback signals in the retina has been known for many years (Thoreson and Burkhardt, 1990; Vigh and Witkovsky, 1999), an effect consistent with the effects of these divalents shown here.

When tested in the isolated goldfish retina, amiloride (200 $\mu \mathrm{M})$ abolished rollback in the $\mathrm{H} 1$ horizontal cell light response (Fig. $7 B$ ). Before application of amiloride, $\mathrm{H} 1$ cells displayed $11 \pm$ $2 \%$ rollback. In the presence of amiloride, rollback was significantly reduced or eliminated ( $p<0.05$; four retinas), and instead a $6 \pm 7 \%$ increase in the hyperpolarizing response was found. In three of the retinas, recordings were possible after washout of amiloride and in these cells rollback recovered $(11 \pm 4 \%)$. The average hyperpolarizing response amplitude under control conditions was $-23 \pm 4 \mathrm{mV}$, in the presence of amiloride was $-16 \pm$ $4 \mathrm{mV}$, and after wash was $-21 \pm 3 \mathrm{mV}$ (means $\pm \mathrm{SEM}$ ). Although the mean values indicate a trend to reduced light responses in amiloride, the differences are not significant (parametric ANOVA and nonparametric tests).

\section{Isolated HCs contain an amiloride-sensitive conductance}

If changes of external $\mathrm{pH}$ in the synaptic cleft deliver the modulatory signal for feedback to cones, the $\mathrm{HC}$ membrane must be capable of regulating proton fluxes in a voltage-dependent manner. We sought to test the feasibility of the proton-feedback model by identifying an HC membrane mechanism consistent with such an action. Considering the results from isolated retina and slices that amiloride blocks feedback, we investigated the possibility that HCs express amiloride-sensitive conductances that would transport protons in the appropriate direction and with appropriate voltage sensitivity. Amiloride-sensitive ENaCs present a reasonable target because these channels are known to conduct protons and are blocked by the divalent cations $\mathrm{Co}^{2+}$ and $\mathrm{Ni}^{2+}$ (Hille, 2001; Sheng et al., 2004).

We isolated goldfish HCs and voltage clamped the membrane with ruptured patch techniques. The basal $I-V$ relationship was dominated by (1) pronounced inward rectification at potentials negative to $-80 \mathrm{mV},(2)$ a steady-state inward current, shown previously to be attributable to $\mathrm{Ca}$ channel activation positive to $-30 \mathrm{mV}$, (3) a transient inward current that activates near -20 $\mathrm{mV}$, and (4) outward rectification positive to $+20 \mathrm{mV}$ (Fig. $8 A, C)$ (Tachibana, 1983). However, over the physiologically important voltage range between -70 and $-40 \mathrm{mV}$, these cells had very low and negative slope conductance $(\sim 300 \mathrm{pS}$, reflecting an input resistance of $-4.4 \pm 0.8 \mathrm{G} \Omega ; n=10)$ that was not decreased by amiloride (Fig. $8 A-C$ ). Figure $8, D$ and $E$, shows an isolated $\mathrm{HC}$ for which, in the presence of $100 \mu \mathrm{M}$ glutamate, whole-cell conductance increased to $1.74 \mathrm{nS}$, and this conductance was reduced $43 \%$ (to $0.98 \mathrm{nS}$ ) when amiloride was added. In a sample of six cells (Fig. $8 \mathrm{~F}$ ), amiloride reduced conductance measured between -70 and $-20 \mathrm{mV}$ in the presence of glutamate from $1.50 \pm 0.61$ to $0.93 \pm 0.27 \mathrm{nS}$, which is on average a $38 \%$ reduction. At the holding potential of $-60 \mathrm{mV}$, the reduction in current from 94 to $60 \mathrm{pA}$ was significant. Glutamate has complex effects on HCs, modulating inward rectification (Kaneko and Tachibana, 1985), increasing AMPA and kainate receptor activity (Lasater, 1986; Shingai and Christensen, 1986), suppressing Ca channel activity via intracellular acidification (Dixon et al., 1993), and enhancing outward rectification (Tachibana, 1983). We are not yet certain of the identity of the amiloride-sensitive conductance, and it will require investigation beyond the scope of this present work to be determined. 

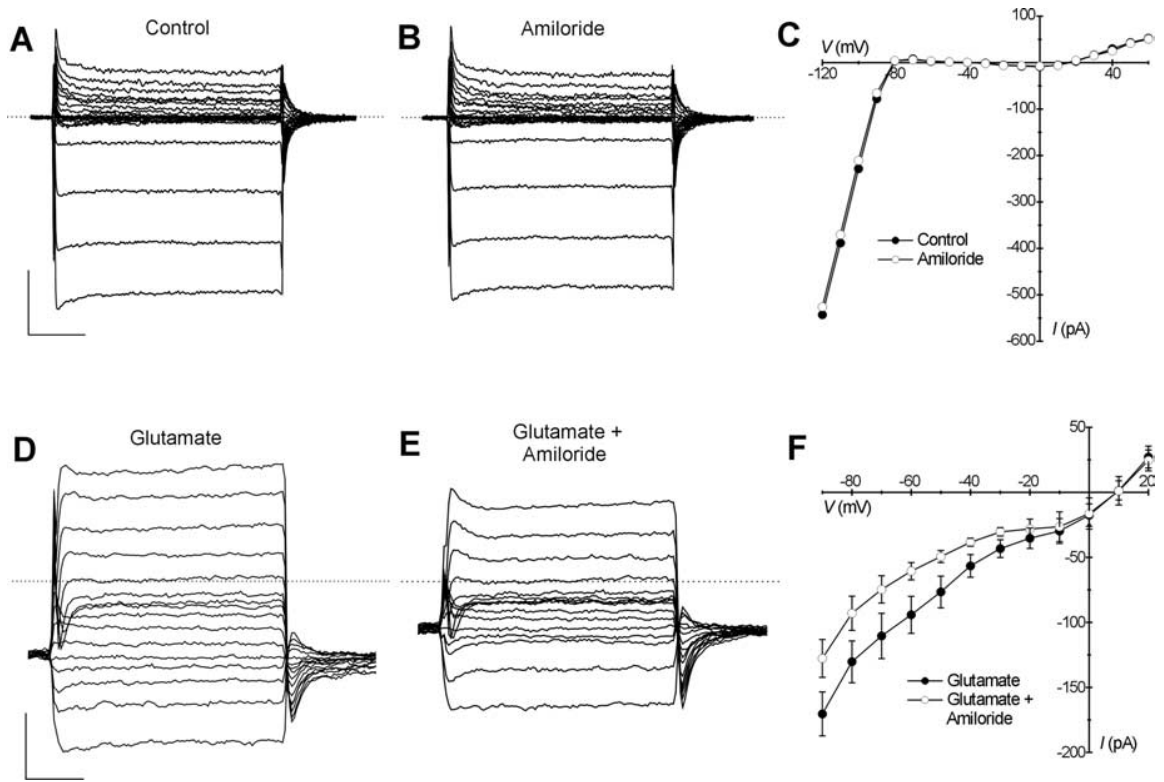

Figure 8. Isolated HCs contain an amiloride-sensitive current. $A$, Currents from a goldfish $\mathrm{HC}$ recorded under voltage clamp at potentials ranging from -120 to $+60 \mathrm{mV}$ in $10 \mathrm{mV}$ step increments from a holding potential of $-60 \mathrm{mV}$. Pronounced inward rectification is apparent at potentials negative to $-80 \mathrm{mV}$. Dotted lines show zero currentlevel. Calibration: $25 \mathrm{~ms}, 200 \mathrm{pA}$. $\boldsymbol{B}$, Currents from the samecell shown in $\boldsymbol{A}$ in the presence of $200 \mu \mathrm{m}$ amiloride. $\boldsymbol{C}$, Current-voltage relationships of steady-state currents from the cell shown in $\boldsymbol{A}$ (Control, filled circles) and $\boldsymbol{B}$ during application of $200 \mu \mathrm{m}$ amiloride (Amiloride, open circles). $\boldsymbol{D}$, Currents from an HC bathed in $100 \mu \mathrm{M}$ glutamate recorded under voltage clamp at potentials ranging from -90 to $+60 \mathrm{mV}$ in $10 \mathrm{mV}$ step increments from a holding potential of $-60 \mathrm{mV}$. Inward and outward rectification is apparent at the extremes of the voltage range, whereas, at the beginning of steps to -10 , 0 , and $+10 \mathrm{mV}$, transient inward currents can be seen. Calibration: $25 \mathrm{~ms}, 100 \mathrm{pA}$. $\boldsymbol{E}$, Currents from the same cell shown in $\boldsymbol{A}$ in the presence of $100 \mu \mathrm{m}$ glutamate and $200 \mu \mathrm{m}$ amiloride. Conductance in the voltage range between -70 and $-20 \mathrm{mV}$ in this cell, decreased from 1.74 to $1.00 \mathrm{nS}$ when amiloride was present. $\boldsymbol{F}$, Mean current-voltage relationships of steady-state currents in six cells showing the response to sustained application of $100 \mu \mathrm{m}$ glutamate (filled circles) and during application of $200 \mu \mathrm{m}$ amiloride with 100 $\mu \mathrm{m}$ or $1 \mathrm{~mm}$ glutamate (open circles).

\section{Discussion}

Synaptic feedback in the outer retina could be encoded by changes in extracellular $\mathrm{pH}$

We describe a near complete reduction in feedback from HCs to cones when $\mathrm{pH}$ buffering power is increased. In $\mathrm{H} 1$ cells, feedback is seen as a rollback of the hyperpolarizing response to light. Increasing bath $\mathrm{pH}$ buffering reduced, eliminated, or even reversed this depolarizing trajectory. In $\mathrm{H} 2$ cells, a depolarizing response to red light arises from the negative feedback of $\mathrm{H} 1$ cells to green cones. When $\mathrm{H} 1$ cells hyperpolarize to red light, this signal is transferred via sign-inverting feedback to green cones, which subsequently feed forward to $\mathrm{H} 2 \mathrm{HCs}$ and produce depolarization. Here again, increasing $\mathrm{pH}$ buffering eliminated the red-induced depolarization as well as increasing the hyperpolarization caused by green light. A hypothetical explanation for these effects is that $\mathrm{HCs}$ regulate $\mathrm{pH}$ in the synaptic cleft and that changes in cleft $\mathrm{pH}$ carry a critical element of the feedback signal to cones that can be quenched by strong $\mathrm{pH}$ buffers.

To frame this hypothesis more precisely, we tested drugs known to depolarize or hyperpolarize HCs and found remarkable actions on presynaptic cone synaptic terminals. Kainate, which typically depolarizes neurons and increases $\left[\mathrm{Ca}^{2+}\right]_{\mathrm{i}}$, dramatically reduced the Ca signals in cones, whereas CNQX, which is known to hyperpolarize HCs and is typically associated with a reduction in Ca signals, unexpectedly produced a marked increase in the depolarization-induced $\mathrm{Ca}$ signals of cone synaptic terminals. The direct effects of these drugs on HC Ca signals were difficult to detect. In fact, kainate-induced increases of $\left[\mathrm{Ca}^{2+}\right]_{\mathrm{i}}$ in $\mathrm{HCs}$ were observed only sporadically because, in general, $\mathrm{HCs}$ did not take up the calcium indicator. This fact also precluded direct observation of a hyperpolarization-induced reduction of $\mathrm{Ca}$ signal in response to CNQX.

\section{$\mathrm{HC}$ membrane potential drives $\mathrm{Ca}$} signal modulation in presynaptic cones We showed that kainate and CNQX push the inhibitory feedback signal in opposing directions, presumably by shifting the presynaptic cone $\mathrm{Ca}$ channel activation curve in the positive or negative direction, respectively (Hirasawa and Kaneko, 2003). These drugs may achieve presynaptic modulation by acting on glutamate receptors found on dendrites of HCs that project into the synaptic invaginations of cone pedicles. The absence of AMPA or kainate receptor subunits on photoreceptors has been shown previously (Tachibana and Kaneko, 1988; Haverkamp et al., 2001a,b; Hirasawa and Kaneko, 2003), and we note that a $\mathrm{Cl}^{-}$conductance increase coupled to glutamate uptake (Sarantis et al., 1988; Arriza et al., 1997) is antagonized by kainate (Eliasof and Werblin, 1993; Eliasof et al., 1998). The lack of any detectable responses in the synaptic terminal layer of the zebrafish retina to the application of kainate in the present studies is consistent with the absence of AMPA receptors in photoreceptors. Kainate, by activating AMPA receptors, depolarizes HCs in the retinal slice. Because the imaging experiments are performed on light-adapted retinas, the HCs should be hyperpolarized and the depolarizing response is quite large. By depolarizing HCs, the feedback inhibition they send to the presynaptic cone $\mathrm{Ca}$ channels is enhanced. Conversely, CNQX antagonizes AMPA receptors, blocking the effects of glutamate released by the cones. This hyperpolarizes HCs further and reduces their inhibitory feedback to cone Ca channels. When revealed with a depolarizing $\left(\mathrm{K}^{+}\right)$stimulus, the calcium signal in the synaptic terminals was suppressed by kainate and enhanced by CNQX, providing evidence of modulation of the inhibitory feedback signal.

\section{Inhibitory feedback from HCs to cones is sensitive to increased $\mathrm{pH}$ buffering and membrane proton flux}

We showed that several specific treatments interfered with the presynaptic Ca signal changes induced by kainate and CNQX. When bicarbonate was added or the concentration of HEPES was increased, extracellular $\mathrm{pH}$ within the retinal slice, including the invaginating synapses, should have been strongly clamped. Were feedback encoded by extracellular protons, this would reduce changes in cleft $\mathrm{pH}$ in response to the application of either kainate or CNQX. Increased HEPES abolished the CNQX-mediated effect and attenuated that of kainate, suggesting that kainate and CNQX lead to shifts in cleft $\mathrm{pH}$ that alter the gating kinetics of the presynaptic cone Ca channels.

In addition to the sensitivity to increased $\mathrm{pH}$ buffering, the inhibitory feedback signal was also found to be sensitive to a reduction in proton driving force. Methazolamide, a carbonic anhydrase inhibitor, blocked the effects of CNQX but not kai- 
nate. By disrupting the ability of $\mathrm{HCs}$ to regulate internal $\mathrm{pH}$ $\left(\mathrm{pH}_{\mathrm{i}}\right)$, it is expected that $\mathrm{pH}_{\mathrm{i}}$ will decrease (as a result of continued cellular metabolism). CNQX, by hyperpolarizing HCs, increases the inward proton driving force and alkalinizes the synaptic cleft, an effect blocked by the accumulation of intracellular protons as a result of methazolamide application. Conversely, by depolarizing HCs, kainate decreases proton driving force permitting the cleft to stay acidified. We postulate that, for this reason, methazolamide was without effect on the cone $\left[\mathrm{Ca}^{2+}\right]_{i}$ response elicited with $\mathrm{HC}$ depolarization.

\section{Presynaptic Ca channels are strongly sensitive to $\mathrm{pH}$}

This work suggests that the HC light responses recorded in intact goldfish retina have the same sensitivity to increases in $\mathrm{pH}$ buffering as the Ca signals recorded optically in retinal slices. What are the most likely targets of protons at the cleft?

The effect of protons on Ca channel gating has been examined (Barnes and Bui, 1991; Barnes et al., 1993; DeVries, 2001). In the current studies, acidic conditions reduced depolarizationinduced calcium signals, whereas basic conditions increased the calcium signals. After testing a range of $\mathrm{pH}$ values, it was possible to estimate the $\mathrm{pH}$ value that kainate and CNQX induce in the cleft. Kainate at $50 \mu \mathrm{M}$ may acidify the cleft to approximately $\mathrm{pH}$ 6.9, whereas $50 \mu \mathrm{M}$ CNQX may alkalinize the cleft to approximately $\mathrm{pH}$ 7.9. A change of $0.1 \mathrm{pH}$ units shifts the activation curve of cone Ca channels by $\sim 1 \mathrm{mV}$ (Barnes and Bui, 1991), and surround illumination shifts the activation curve of the Ca channels negatively by $\sim 7.5 \mathrm{mV}$ (Verweij et al., 1996). Therefore, modulation of cleft $\mathrm{pH}$ by kainate and CNQX appears consistent with a proton-mediated mechanism of inhibitory feedback on $\mathrm{Ca}$ channels.

We note that we may have overestimated the $\mathrm{pH}$ changes responsible for presynaptic Ca signaling in feedback: recordings of isolated cones and HCs in slices show that Ca channel activity is sufficiently suppressed at pH 6.9 to eliminate synaptic transmission at this synapse (Barnes and Bui, 1991; Barnes et al., 1993).

\section{Horizontal cells could modulate cleft $\mathrm{pH}$ via an amiloride- sensitive proton channel}

The extracellular compartment of the outer retina is known to undergo a light-induced alkalinization (Borgula et al., 1989; Oakley and Wen, 1989; Yamamoto et al., 1992). These measurements are consistent with the general principal that depolarization increases metabolic load on cells, and this leads to an increase in the production and extrusion of protons. Two reports suggest that glutamate reduces proton efflux from isolated HCs (Dixon et al., 1993; Molina et al., 2004), a finding in contrast to what this proton model of feedback requires. This efflux is coupled to $\mathrm{Ca}$ ATPase activity and is observed when cells are bathed in a strongly pH-buffered environment (a proton sink). With weaker proton buffering and a restricted extracellular volume, conditions of elevated cleft proton concentration would lead to proton influx via proton-permeable channels. There are multiple sources of cleft protons associated with cell metabolism, and protons are released from cones along with vesicular glutamate (DeVries, 2001).

Estimates put the volume of the invaginating synaptic cleft in the range of $3 \times 10^{-18} \mathrm{~L}$ (Raviola and Gilula, 1975), a volume in which approximately two protons give rise to a $\mathrm{pH}$ of 6 . Because it has been shown that vesicular release produces a significant source of protons in the cleft at ribbon synapses in cones (DeVries, 2001) and bipolar cells (Palmer et al., 2003), given the partial protonation of vesicular glutamate molecules (intravesicular $\mathrm{pH} \sim 5.7 ; \mathrm{p}_{\mathrm{Ka}}$ of glutamate carboxyl side chain of 4.4) and a dark release rate estimated at $400 \mu \mathrm{M} / \mathrm{s}$ (Roska et al., 1998) into an $\sim 3 \times 10^{-18} \mathrm{~L}$ volume, the flux of protons to maintain steadystate $\mathrm{pH}$ could be in the range of $\sim 40$ protons per second per cleft. This flux represents an extremely small current $(0.006 \mathrm{fA})$ to be accommodated by a proton conductance. To alkalinize the cleft during HC hyperpolarization, slightly larger fluxes would need to be accommodated.

Amiloride-sensitive channels, such as ENaCs, would be suitable candidates for the $\mathrm{HC} \mathrm{pH}$-regulating mechanism. Amiloride is known to inhibit some ENaCs (Garty and Palmer, 1997), acid sensing ion channels (Waldmann et al., 1997), transient receptor potential channels (Inoue et al., 2001; Vulcu et al., 2004), and glutamate-gated channels (Manev et al., 1990). Divalent cations have been shown to block inhibitory feedback from HCs, and no conclusive explanation for this has been put forth (Thoreson and Burkhardt, 1990; Vigh and Witkovsky, 1999; Fahrenfort et al., 2004). Divalent cations block ENaC currents (Sheng et al., 2002). Our imaging of $\mathrm{Ca}$ signals demonstrated sensitivity to both divalent cations and amiloride. We also showed that amiloride blocks the rollback in $\mathrm{H} 1$ cells and reduces whole-cell currents in isolated HCs. ENaCs also display a high proton conductance (Hille, 2001), necessary for a role in extracellular $\mathrm{pH}$ regulation. $\mathrm{ENaC}$ subunits have been shown to be present in the retina with molecular and immunological techniques (Mirshahi et al., 1999; Golestaneh et al., 2000), and the $\alpha$-subunit of the ENaC family is expressed in the outer plexiform layer (Brockway et al., 2002). Although the outer retina presents a diversity of targets for amiloride (and the other agents tested), these data are consistent with the notion that an $\mathrm{HC}$ proton conductance underlies generation of the voltage-dependent feedback response.

\section{References}

Aickin CC, Thomas RC (1977) The effect of external Na and amiloride on pHi recovery in mouse soleus muscle. J Physiol (Lond) 269:80P-81P.

Arriza JL, Eliasof S, Kavanaugh MP, Amara SG (1997) Excitatory amino acid transporter 5, a retinal glutamate transporter coupled to a chloride conductance. Proc Natl Acad Sci USA 94:4155-4160.

Baldridge WH (1996) Optical recordings of the effects of cholinergic ligands on neurons in the ganglion cell layer of mammalian retina. J Neurosci 16:5060-5072.

Barnes S, Bui Q (1991) Modulation of calcium-activated chloride current via $\mathrm{pH}$-induced changes of calcium channel properties in cone photoreceptors. J Neurosci 11:4015-4023.

Barnes S, Merchant V, Mahmud F (1993) Modulation of transmission gain by protons at the photoreceptor output synapse. Proc Natl Acad Sci USA 90:10081-10085.

Baylor DA, Fuortes MG, O'Bryan PM (1971) Receptive fields of cones in the retina of the turtle. J Physiol (Lond) 214:265-294.

Borgula GA, Karwoski CJ, Steinberg RH (1989) Light-evoked changes in extracellular $\mathrm{pH}$ in frog retina. Vision Res 29:1069-1077.

Brockway LM, Zhou ZH, Bubien JK, Jovov B, Benos DJ, Keyser KT (2002) Rabbit retinal neurons and glia express a variety of ENaC/DEG subunits. Am J Physiol Cell Physiol 283:C126-C134.

Burkhardt DA (1993) Synaptic feedback, depolarization, and color opponency in cone photoreceptors. Vis Neurosci 10:981-989.

Chen XH, Bezprozvanny I, Tsien RW (1996) Molecular basis of proton block of L-type $\mathrm{Ca}^{2+}$ channels. J Gen Physiol 108:363-374.

Chow SY, Yen-Chow YC, White HS, Woodbury DM (1991) pH regulation after acid load in primary cultures of mouse astrocytes. Brain Res Dev Brain Res 60:69-78.

Chow SY, Yen-Chow YC, Woodbury DM (1992) Studies on pH regulatory mechanisms in cultured astrocytes of DBA and C57 mice. Epilepsia 33:775-784.

Connaughton VP, Maguire G (1998) Differential expression of voltagegated $\mathrm{K}^{+}$and $\mathrm{Ca}^{2+}$ currents in bipolar cells in the zebrafish retinal slice. Eur J Neurosci 10:1350-1362. 
DeVries SH (2001) Exocytosed protons feedback to suppress the $\mathrm{Ca}^{2+}$ current in mammalian cone photoreceptors. Neuron 32:1107-1117.

Dixon DB, Takahashi K, Copenhagen DR (1993) L-Glutamate suppresses HVA calcium current in catfish horizontal cells by raising intracellular proton concentration. Neuron 11:267-277.

Eliasof S, Werblin F (1993) Characterization of the glutamate transporter in retinal cones of the tiger salamander. J Neurosci 13:402-411.

Eliasof S, Arriza JL, Leighton BH, Kavanaugh MP, Amara SG (1998) Excitatory amino acid transporters of the salamander retina: identification, localization, and function. J Neurosci 18:698-712.

Fahrenfort I, Sjoerdsma T, Ripps H, Kamermans M (2004) Cobalt ions inhibit negative feedback in the outer retina by blocking hemichannels on horizontal cells. Vis Neurosci 21:501-511.

Garty H, Benos DJ (1988) Characteristics and regulatory mechanisms of the amiloride-blockable $\mathrm{Na}^{+}$channel. Physiol Rev 68:309-373.

Garty H, Palmer LG (1997) Epithelial sodium channels: function, structure, and regulation. Physiol Rev 77:359-396.

Golestaneh N, Nicolas C, Picaud S, Ferrari P, Mirshahi M (2000) The epithelial sodium channel $(\mathrm{ENaC})$ in rodent retina, ontogeny and molecular identity. Curr Eye Res 21:703-709.

Hare WA, Owen WG (1998) Effects of bicarbonate versus HEPES buffering on measured properties of neurons in the salamander retina. Vis Neurosci 15:263-271.

Haugh-Scheidt L, Ripps H (1998) pH regulation in horizontal cells of the skate retina. Exp Eye Res 66:449-463.

Haverkamp S, Grunert U, Wassle H (2001a) Localization of kainate receptors at the cone pedicles of the primate retina. J Comp Neurol 436:471-486.

Haverkamp S, Grunert U, Wassle H (2001b) The synaptic architecture of AMPA receptors at the cone pedicle of the primate retina. J Neurosci 21:2488-2500.

Hille B (2001) Ion channels of excitable membranes, Ed 3, p 294. Sunderland, MA: Sinauer.

Hirasawa H, Kaneko A (2003) pH changes in the invaginating synaptic cleft mediate feedback from horizontal cells to cone photoreceptors by modulating $\mathrm{Ca}^{2+}$ channels. J Gen Physiol 122:657-671.

Inoue R, Okada T, Onoue H, Hara Y, Shimizu S, Naitoh S, Ito Y, Mori Y (2001) The transient receptor potential protein homologue TRP6 is the essential component of vascular alpha(1)-adrenoceptor-activated $\mathrm{Ca}^{2+}$ permeable cation channel. Circ Res 88:325-332.

Kamermans M, Spekreijse H (1999) The feedback pathway from horizontal cells to cones. A mini review with a look ahead. Vision Res 39:2449-2468.

Kaneko A, Tachibana M (1985) Effects of L-glutamate on the anomalous rectifier potassium current in horizontal cells of Carassius auratus retina. J Physiol (Lond) 358:169-182.

Klockner U, Isenberg G (1994) Calcium channel current of vascular smooth muscle cells: extracellular protons modulate gating and single channel conductance. J Gen Physiol 103:665-678.

Krafte DS, Kass RS (1988) Hydrogen ion modulation of Ca channel current in cardiac ventricular cells. Evidence for multiple mechanisms. J Gen Physiol 91:641-657.

Lasater EM (1986) Ionic currents of cultured horizontal cells isolated from white perch retina. J Neurophysiol 55:499-513.

Liu Y, Edwards RH (1997) The role of vesicular transport proteins in synaptic transmission and neural degeneration. Annu Rev Neurosci 20:125-156.

Manev H, Bertolino M, DeErausquin G (1990) Amiloride blocks glutamateoperated cationic channels and protects neurons in culture from glutamate-induced death. Neuropharmacology 29:1103-1110.

Mirshahi M, Nicolas C, Mirshahi S, Golestaneh N, d'Hermies F, Agarwal MK (1999) Immunochemical analysis of the sodium channel in rodent and human eye. Exp Eye Res 69:21-32.

Molina AJ, Verzi MP, Birnbaum AD, Yamoah EN, Hammar K, Smith PJ, Malchow RP (2004) Neurotransmitter modulation of extracellular $\mathrm{H}^{+}$fluxes from isolated retinal horizontal cells. J Physiol (Lond) 560:639-657.

Morigiwa K, Vardi N (1999) Differential expression of ionotropic glutamate receptor subunits in the outer retina. J Comp Neurol 405:173-184.
Oakley B, Wen R (1989) Extracellular pH in the isolated retina of the toad in darkness and during illumination. J Physiol (Lond) 419:353-378.

Palmer MJ, Hull C, Vigh J, von Gersdorff H (2003) Synaptic cleft acidification and modulation of short-term depression by exocytosed protons in retinal bipolar cells. J Neurosci 23:11332-11341.

Piccolino M, Gerschenfeld HM (1980) Characteristics and ionic processes involved in feedback spikes of turtle cones. Proc R Soc Lond B Biol Sci 206:439-463.

Prod'hom B, Pietrobon D, Hess P (1987) Direct measurement of proton transfer rates to a group controlling the dihydropyridine-sensitive $\mathrm{Ca}^{2+}$ channel. Nature 329:243-246.

Raviola E, Gilula NB (1975) Intramembrane organization of specialized contacts in the outer plexiform layer of the retina. J Cell Biol 65:192-222.

Roska B, Gaal L, Werblin FS (1998) Voltage-dependent uptake is a major determinant of glutamate concentration at the cone synapse: an anatomical study. J Neurophysiol 80:1951-1960.

Sarantis M, Everett K, Attwell D (1988) A presynaptic action of glutamate at the cone output synapse. Nature 332:451-453.

Sheng S, Perry CJ, Kleyman TR (2002) External nickel inhibits epithelial sodium channel by binding to histidine residues within the extracellular domains of alpha and gamma subunits and reducing channel open probability. J Biol Chem 277:50098-50111.

Shingai R, Christensen BN (1986) Excitable properties and voltage-sensitive ion conductances of horizontal cells isolated from catfish (Ictalurus punctatus) retina. J Neurophysiol 56:32-49.

Stell WK (1975) Horizontal cell axons and axon terminals in goldfish retina. J Comp Neurol 159:503-520.

Stell WK, Harosi FI (1976) Cone structure and visual pigment content in the retina of the goldfish. Vision Res 16:647-657.

Stell WK, Lightfoot DO (1975) Color-specific interconnections of cones and horizontal cells in the retina of the goldfish. J Comp Neurol 159:473-502.

Stell WK, Lightfoot DO, Wheeler TG, Leeper HF (1975) Goldfish retina: functional polarization of cone horizontal cell dendrites and synapses. Science 190:989-990.

Sun X, Barnes S, Baldridge WH (2002) Adenosine inhibits calcium channel currents via A1 receptors on salamander retinal ganglion cells in a minislice preparation. J Neurochem 81:550-556.

Tachibana M (1983) Ionic currents of solitary horizontal cells isolated from goldfish retina. J Physiol (Lond) 345:329-351.

Tachibana M, Kaneko A (1988) L-Glutamate-induced depolarization in solitary photoreceptors: a process that may contribute to the interaction between photoreceptors in situ. Proc Natl Acad Sci USA 85:5315-5319.

Thoreson WB, Burkhardt DA (1990) Effects of synaptic blocking agents on the depolarizing responses of turtle cones evoked by surround illumination. Vis Neurosci 5:571-583.

Twig G, Levy H, Perlman I (2003) Color opponency in horizontal cells of the vertebrate retina. Prog Retin Eye Res 22:31-68.

Verweij J, Kamermans M, Spekreijse H (1996) Horizontal cells feed back to cones by shifting the cone calcium-current activation range. Vision Res 36:3943-3953.

Vigh J, Witkovsky P (1999) Sub-millimolar cobalt selectively inhibits the receptive field surround of retinal neurons. Vis Neurosci 16:159-168.

Vulcu SD, Liewald JF, Gillen C, Rupp J, Nawrath H (2004) Proton conductance of human transient receptor potential-vanilloid type-1 expressed in oocytes of Xenopus laevis and in Chinese hamster ovary cells. Neuroscience 125:861-866.

Waldmann R, Champigny G, Bassilana F, Heurteaux C, Lazdunski M (1997) A proton-gated cation channel involved in acid-sensing. Nature 386:173-177.

Wu SM (1992) Feedback connections and operation of the outer plexiform layer of the retina. Curr Opin Neurobiol 2:462-468.

Yamamoto F, Borgula GA, Steinberg RH (1992) Effects of light and darkness on $\mathrm{pH}$ outside rod photoreceptors in the cat retina. Exp Eye Res 54:685-697. 